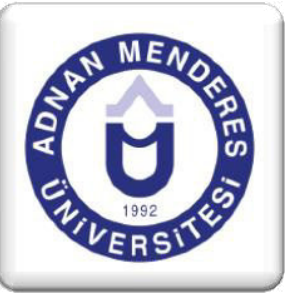

\title{
Türkiye'de 6360 Sayılı Yasa İle Yeni Kurulan Büyükşehir Belediyeleri: Manisa Büyükşehir Belediyesi Örneği
}

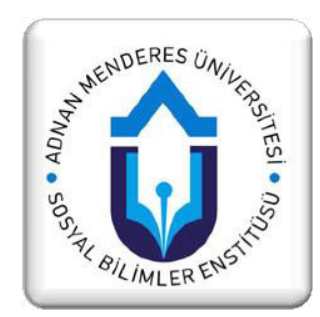

\section{Özet}

Hızlı kentleşme sonucunda büyük kentlerin daha çok büyümesi belediye sınırları dışında düzensiz ve plansız gelişmelere yol açınca, Türkiye'de büyükşehirlerin yönetiminde özel modeller arayışı güncellik kazanmıştır. Bu bağlamda 1984 yılında İstanbul, Izmir ve Ankara; 1986 yılında Adana; 1987 yılında Bursa, Konya, Gaziantep; 1988 yılında Kayseri; 1993 yılında Samsun, Diyarbakır, Erzurum, İmit (Kocaeli), Eskişehir, Mersin ve Antalya; 2000 yılında da Sakarya (Adapazarl) Belediyeleri; büyükşehir belediyelerine dönüştürülmüştür. 2012 yılında çıkarılan 6360 sayılı yasa ile 16 olan büyükşehir belediyesi sayısı 29'a çıkarılmıştır. 6360 sayılı yasa ile Aydın, Balıkesir, Denizli, Hatay, K. Maraş, Mardin, Malatya, Manisa, Muğla, Tekirdağ, Trabzon, Şanlıurfa ve Van illerinin belediyeleri büyükşehir statüsüne kavuşmuştur.

2013 yılının Mart ayında çıkarılan 6447 sayılı yasa ile Ordu ili de büyükşehir statüsüne kavuşmuş böylece bu yasaların 30 Mart 2014 tarihinde yürürlüğe girmesiyle birlikte Türkiye'deki büyükşehir belediye sayısı 30'a yükselmiştir. Bu çalışmada 6360 Sayllı Yasa'nın yürürlüğe girmesiyle birlikte büyükşehir belediyesi statüsüne kavuşmuş olan Manisa'nın genel tanıtımı (yerleşim, nüfus, gelişmişlik vb. açılardan) yapılmakta, kentin mekânsal gelişimi, kentte belediyeciliğin tarihi gelişimi, kentin büyükşehir olma süreci, kentin büyükşehir olması sonrasındaki durum ortaya konulmaktadır.

Anahtar Kelimeler: Büyükşehir belediye sistemi, belediye, Manisa Büyükşehir Belediyesi, 6360 Sayll Yasa

\section{Mustafa \\ ÖKMEN*}

Recep

ARSLAN**

*Prof. Dr.

Celal Bayar Üniversitesi

Kamu Yönetimi Bölümü

**öğr. Gör

Celal Bayar Üniversitesi Salihli MYO 


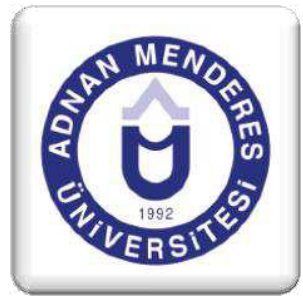

\section{Newly Established Metropolitan Municipalities in Turkey with the Law No. 6360: Manisa Municipality Example}

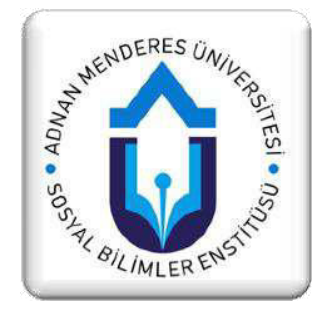

\section{Abstract}

In search of specific models in management of metropolitan municipalities in Turkey has gained popularity in consequence of further expansion of big/large cities rather outside the municipal boundaries due to rapid urbanization leads irregular and unplanned development. In this context, Istanbul, Izmir and Ankara in 1984; Adana in 1986; Bursa, Konya, Gaziantep in 1987; Kayseri in 1988; Samsun, Diyarbakır, Erzurum, Izmit (Kocaeli), Eskişehir, Mersin and Antalya in 1993, and Sakarya (Adapazari) Municipalities in 2000 was converted to metropolitan municipalities With the law numbered 6360 enacted in 2012, the number of metropolitan municipalities which was 16 has been increased to 29. With Law Number 6360, Aydın, Balıkesir, Denizli, Hatay, K. Maras, Mardin, Malatya, Manisa, Muğla, Tekirdağ, Trabzon, Şanlıurfa and Van Sanliurfa and Van provinces gained the status of metropolitan municipalities.

With the law numbered 6447 issued in March of 2013, Ordu has also gained the status of metropolitan so with these laws go into effect on March 30, 2014 the number of metropolitan municipalities in Turkey has increased to 30. In this study, with the enactment of Law Number 6360, general presentation (in terms of settlement, population, development and etc.) of Manisa which has gained the status of metropolitan municipality is made and spatial development of the city, municipal development in the city's history, the city's process of becoming metropolitan, after that the city's metropolitan status is presented.

Keywords: Municipality policy, municipality, Manisa Municipality, Law Number 6360

\section{Mustafa \\ ÖKMEN*}

Recep

ARSLAN**

*Prof. Dr.

Celal Bayar Üniversitesi

Kamu Yönetimi Bölümü

**Öğr. Gör

Celal Bayar Üniversitesi

Salihli MYO 


\section{GíRiş}

Türkiye'de metropolitan alan yönetiminin geçmişi, Osmanlı'da belediye yönetiminin ilk kuruluş yıllarına kadar gider. 1855'te kurulan ilk belediye örgütü, 1869 tarihli bir tüzük ile tüm İstanbul'a yaygınlaştırılırken, iki kademeli bir yönetim modeli oluşturulmuştur. İlk kademe belediyelerinde seçimle oluşan bir belediye dairesi meclisi ile bu meclisin seçilmiş üyeleri arasından merkezi yönetimce atanan bir belediye meclisi reisi bulunmaktaydı. Cumhuriyet döneminde de 1930 sayılı Belediye Yasası yürürlükte iken, büyükşehir yönetim denemeleri yapılmıştır (Gül, 2013: 29). Türkiye'de büyükşehir belediye modelinin uygulanmaya başlandığı y1l 1984'tür. Zira 1960'lı yılların ikinci yarısından itibaren büyükşehirler konusunda bir arayış dönemine girilmiştir (Arıkboğa, 2013: 50-51). 1982 Anayasası'nın mahalli idareler başlıklı 127. maddesinde "Kanun, büyük yerleşim yerleri için özel yönetim biçimleri getirebilir" denmektedir.

Anayasa'ya bu hüküm girdikten sonra 1984'te ülkemizde Büyükşehir Belediyesi modeli uygulanmaya başlanmıştır. 2012 yılındaki değişikliklerle birlikte ise artık yeni bir dönem başlamıştır (Arıkboğa, 2013:51). 2012 yılında çıkarılan 6360 sayılı 13 İlde Büyükşehir Belediyesi ve 26 İlçe Kurulması ile Bazı Kanun ve Kanun Hükmünde Kararnamelerde Değişiklik Yapılmasına Dair Kanun ve 2013 yılında çıkarılan 6447 sayılı 13 On Üç İlde Büyükşehir Belediyesi ve Yirmi Altı İlçe Kurulması İle Bazı Kanun ve Kanun Hükmünde Kararnamelerde Değişiklik Yapılmasına Dair Kanun'da Değişiklik Yapılması Hakkında Kanun'la, büyükşehir belediyesi sayısı 16'dan 30'a çıkmıştır.

6360 Sayılı Yasa ile birlikte bütün büyükşehir belediye sınırları il mülki sınırı olmuştur. Büyükşehirlerdeki il özel idareleri ile belde belediyeleri kaldırılmıştır ve köy yönetimleri mahalleye dönüştürülmüştür. Valiliklere bağlı olarak 30 ilde Yatırım İzleme ve Koordinasyon Başkanlığı kurulmuştur. Büyükşehir Belediyesi dişındaki illerde nüfusu 2000'den az olan belde belediyeleri köye dönüştürülmüştür. Bunların sayısı 559 idi, ancak 33 tanesi yasa yürürlüğe girene kadar birleşme yoluyla nüfusunu artırmayı başarmıştır (Arıkboğa, 2013: 51).

6360 Sayılı Yasa'nın yürürlüğe girmesiyle birlikte büyükşehir belediye sayısı 16'dan 30'a, büyükşehir ilçe belediyesi sayısı ise 143 'ten 519 'a çıkmıştır. İl belediye sayısı 65 'den 51'e, ilçe belediye say1s1 749'dan 400'e, belde belediye sayıs1 1.977 'den 396'ya düşmüştür. Toplamda ise belediye sayıs 2.950'den 1396'ya düşmüştür. İl özel idarelerinin sayıs1 81'den 51'e, köy sayıs1 da 34.283'den 17.720'ye düşmüştür (Çelik ve Altıparmak, 2013: 220). 6360 Sayılı Yasa'nın yürürlüğe girmesinden önce Türkiye nüfusunun \% 83'ü belediye sınırları içerisinde, \% 17'si belediye sınırları dışında yaşamaktaydı. Belediye sınırları içerisinde yaşayanların \% 55'i büyükşehir belediyesi, \% 45'i diğer belediye sınırları içerisinde bulunmaktayd1. 6360 Sayılı Yasa ile birlikte Türkiye'nin \%7 8'ine denk gelen 56 milyon kişi büyükşehir belediye sınırları içinde yaşamaya başlamıştır. 30 Mart 2014 yerel seçimlerinden sonra ülke nüfusunun \% 92'si belediye sınırlarında, \% 8'i ise köylerde yaşamaktadır. 6360 sayılı yasa Türkiye'de yaşayan her 4 kişiden 3'ünü ilgilendirmektedir (Çelik ve Altıparmak 2013: 23).

6360 sayılı yasa yürürlüğe girmeden önce Manisa İlinde mülki yönetim birimi olarak merkez dahil 16 ilçe, 68 belde, 648 tanesi orman köyü olmak üzere 780 köy bulunmaktaydı (Çelik ve Altıparmak, 2013:219). Manisa'da yerel yönetim birimi olarak 1'i il, 15 ilçe, 68'i kasaba (belde) olmak üzere toplam 84 belediye bulunmaktaydı (Manisa Valiliği, 2007: 95). Manisa, belediye sayısı bakımından Türkiye'de en fazla belediyeye sahip 5.il, köy sayısı bakımından ise en fazla köye sahip 8. il konumunda idi.

6360 Sayılı Yasa'nın yürürlüğe girmesiyle birlikte Manisa ilinde ilçe sayısı 17'ye çıkmıştır. 6360 sayılı Kanunla Manisa'da, Merkez ilçe; köy, mahalle ve beldeleri ile birlikte ikiye bölünerek Şehzadeler ve Yunusemre adıyla iki yeni ilçe oluşturulmuştur.

\section{MANISA HAKKINDA GENEL BÍLGi}

Manisa kenti Ege Bölgesinin batı kesiminde Manisa Dağı eteğinde, Gediz ırmağının geçtiği Manisa ovası kenarında kurulmuştur (Manisa Belediyesi, 2010:3). Manisa ili topraklarının büyük bölümü Gediz Havzası içinde, küçük bir bölümü de kuzeybatıda Ege (Bakırçay) Havzası içinde bulunmaktadır. Manisa 27 $08^{\prime}$ ve 29 05' doğu boylamları ile 38 04' ve 39 58' kuzey enlemleri arasında yer alır. İdari yönden batıdan 
İzmir, kuzeyden Balıkesir, güneyden Aydın, güneydoğudan Denizli, doğudan Uşak ve Kütahya illeri ile çevrilidir (Manisa Valiliği, 1973: 18). İlin yüzölçümü 13.810 km² dir. İzmir'den sonra Ege Bölgesi'nin 2. büyük ilidir. "Şehzadeler Şehri" olarak da bilinir. Şifalı Mesir Macunu ve Sultaniye üzümü ile tanınır. Manisa adının Yunanistan'da Teselya Bölgesi doğusunda, Magnesia'da yaşayan Magnetlerle ilişkili oldukları sanılmaktadır. Yunan tarihçilerine göre Magnetler Anadolu'ya gelerek, biri Büyük Menderes (Maiandro) diğeri de Gediz (Hermos) kıyısında iki kent kurmuşlardır. Gediz kıyısında Sipilos Dağı'nın kuzey eteklerinde kurulan kent "Magnesia upo sipilo" adıyla anılmaktadır. Bu ad Roma döneminde "Magnesia ad Sipylum" olmuştur. Manisa adı da Magnesia sözcüğünün değişime uğramasıyla bugünkü şeklini almıştır (Manisa Çevre İl Müdürlüğü, 1998: 47)

Manisa ilinde 17 adet ilçe bulunmaktadır. Bunlar: Ahmetli, Akhisar, Alaşehir, Demirci, Gölmarmara, Gördes, Kırkağaç, Köprübaşı, Kula, Salihli, Sarıgöl, Saruhanlı, Selendi, Soma, Şehzadeler, Turgutlu ve Yunusemre'dir. Şehzadeler ve Yunusemre 6360 sayılı yasa ile yeni kurulan ilçelerdir. Manisa ilinin nüfusu, 2013 yılı Adrese Dayalı Nüfus Kayıt Sistemi (ADNKS) sonuçlarına göre 1.359.463 kişidir. Manisa merkez nüfusu 364.332'dir (Şehzadeler ve Yunusemre ilçeleri hariçtir). İlin nüfus yoğunluğu ise $\mathrm{km}^{2}$ başına 104 kişidir. Manisa'nın nüfus bakımından en büyük beş ilçesi sırasıyla Yunusemre (199.683), Şehzadeler (164.649), Akhisar (161.918), Salihli (156.330) ve Turgutlu'dur (148.130). Nüfus bakımından en küçük ilçesi ise Köprübaşı'dır (14.045).

Manisa ilinin nüfusu, 2012 Adrese Dayalı Nüfus Kayıt Sistemi sonuçlarına göre ise 1.346 .162 kişidir. Nüfusun 904.513 kişisi şehirlerde yaşarken, 441.649 kişisi belde ve köylerde yaşamaktadır. Şehirde yaşayanların oranı \% 67.19, köyde yaşayanların oranı \% 32.81'dir. 2012 verilerine göre il merkezi nüfusu 356.702'dir. Yüzölçümü bakımından ise en büyük ilçesi Akhisar iken en küçük ilçesi Gölmarmara'dır. Manisa nüfus bakımında Türkiye'nin 14. büyük ilidir. Kent merkezi olarak Türkiye'nin en yoğun göç alan şehirlerinden birisidir.

İzmir'e yakınlığının da sağladığı avantajlarla hızla gelişen bir merkezdir. Türkiye'nin en gelişmiş ve en büyük organize sanayi bölgelerinden birisine sahiptir. Bölgenin İzmir'den sonra ikinci büyük sanayi ve ticaret merkezidir. Manisa Organize Sanayi Bölgesi'nden dünyanın 100'ü aşkın ülkesine ihracat yapılmaktadır. Türkiye'de faaliyet gösteren en büyük 500 firmadan 26 tanesi Manisa'dadır (Manisa Valiliği, 2014: 82). 2013 yılında en çok ihracat yapan iller arasında 7. sıradadır ${ }^{1}$ Ülkemizde üretilen çekirdeksiz kuru üzümün yüzde $88^{\prime} i$, tütünün yüzde $43^{\prime}$ ü, zeytinin yüzde 19 'u Manisa'da üretilmektedir. Mesir Macunu Festivali UNESCO tarafından "İnsanlığın Somut Olmayan Kültürel Mirası Temsili Listesi'ne alınmıştır (Ökmen ve diğerleri, 2014: 72).

Manisa ilinde 2001 rakamlarına göre kişi başına gayri safi yurtiçi hasıla (cari fiyatlarla) 2.459 ABD Doları'dır² 2008 yılında kişi başına gayri safi katma değer 8.256 ABD Doları olarak gerçekleşmiştir. Bu değer 9.384 Dolar olan Türkiye değerinin altındadır (TÜIK, 2013:5). Manisa Valiliği’nin hazırlattığ1 Sayılarla Manisa 2013 raporuna göre kentteki işsizlik oranı \% 9,7, tarım dışı işsizlik oranı ise \% 12'dir (Manisa Valiliği, 2014: 53). Kalkınma Bakanlığı tarafından hazırlanan SEGE 2011 verilerine göre illerin sosyo-ekonomik gelişmişlik sıralamasında ise 81 il içinde 23. sıradadır ${ }^{3}$.

\section{KENTIN MEKANSAL GELIŞíi I}

Manisa kenti Ege Bölgesinin batı kesiminde Manisa Dağı eteğinde, Gediz ırmağının geçtiği Manisa ovası kenarında kurulmuştur (Manisa Belediyesi, 2010:3). Manisa doğal açıdan, kuzey ve kuzeydoğudan Demirci Dağları ve uzantıları, doğudan Kula-Gördes-Uşak platoları, güneyden Bozdağlar, batıdan Spil Dağı, Yamanlar Dağı uzantıları, Menemen Boğazı ve Yunt Dağı uzantılarıyla sınırlanmış durumdadır. İlin

\footnotetext{
${ }^{1}$ (http://gen.tobb.org.tr/ggnot/images/bilgi_notu/828_Aral\%C4\%B1k2013D\%C4\%B1sTicaretIstatistikleri.pdf).

2 (http://www.tuik.gov.tr/VeriTabanlari.do?ust_id=113\&vt_id=45).

${ }^{3}$ (http://www3.kalkinma.gov.tr/PortalDesign/PortalControls/WebIcerikGosterim.aspx?Enc=83D5A6FF03C7B4FC4312

1E8457331356).
} 
toprakları çok büyük bir ağırlıkla dağlar ve platolardan oluşmuştur. Gölmarmara Gölü, Demirköprü Barajı ile Gediz ve Bakırçay nehirleri ilin önemli su kaynaklarıdır.

Doğu kesimindeki dağlar Kula-Gördes Platosu üzerinde alçalarak ovaya inerken, güney kesimindeki dağlar dik yamaçlarla ovadan ayrılmaktadır. Spil Dağı doğu-batı doğrultusunda uzanan dağ kütlesi, güney ve batıdan zengin bitki örtüsüne sahip yamaçlarla, kuzeyden ise fay diklikleri ile sınırlanmaktadır. İzmirManisa il sınırını oluşturan Yunt Dağı, Bakırçay ve Gediz vadileri arasında yükselen bir kütledir. Bozdağlar, Manisa-İzmir il sınırını oluşturan düzenli bir sıradır. Demirci Dağları, Manisa ilinin Kütahya ve Balıkesir illeriyle sınırı durumundadır (TÜİK, 2013:XIII).

Manisa il topraklarının \% 46'sı orman ve makilerle kaplıdır. Ormanlar genelde $1000 \mathrm{~m}$. üzerindeki yüksekliklerde bulunur. İl topraklarının \% 39,1'i ekili ve dikili arazi, \% 7'si çayır ve meralardan, \% 8'i tarıma elverişsiz alanlardan ibarettir. Manisa il alanının genel çizgilerini belirleyen özelliklerin başında, vadiler ve üzerlerindeki ovalar gelmektedir (TÜİK, 2013: XIV). Kentin önünde, Gediz vadisi ve ovasının devamı olarak doğuya ve kuzeye uzanan Manisa ovası, akarsuların ve sellerin getirdiği alüvyonlarla dolduğu için oldukça verimlidir. Uzunluğu 30 genişliği 15 kilometre olan Manisa ovasının bir kısmı son yıllarda kent yönünden başlayan genişleme ile sanayi ve yerleşim alanı haline gelmiştir. Gediz çökme çukurunun üzerindeki Manisa ovasının şehrin içinden geçen güney sınırı aynı zamanda fay hattıdır. Manisa'da bilinen en büyük fay Manisa Ovası ve Spil dağını sınırlayan faydır (Manisa Fayı). Gediz grabenini oluşturan fay sisteminin devamı olan bu fay olası aktif özellik taşımaktadır. Fayın güney kesiminde eğimin yüksek olmasından kaynaklanan değişik boyutta pek çok heyelan gözlenmektedir. Gerek Manisa ilinin tamamı gerekse birinci derece deprem bölgesindedir. Manisa'nın kentsel gelişimi; yukarıda belirttiğimiz, üzerinde kurulup geliştiği topoğrafyanın imkan ve sınırlılıkları tarafından belirlenmiştir. Kent Manisa Dağı ve Gediz Nehri ile kuzey ve güney yönlerden kısıtlanmıştır. Şehre gelişim alanı olarak dar bir şerit (Manisa Belediyesi, 2010: 3) halinde batı-güneybatı yönü kalmaktadır. Şehrin doğu yönünde ise kuraldışı bir yapılaşma gelişmiştir.

Ülkemizde 1960'lardan itibaren tarımdaki makineleşme sonucu kırsal iş olanaklarının azalması ve yatırımların ülke çapında dengesiz dağılımı kentlere göç olayını hızlandırmıştır. Manisa genelinde ülke geneline paralel olarak kırsal kesimden özellikle istihdam verebilen ilçe merkezlerine nüfus akışı meydana gelmektedir. Manisa merkez başta olmak üzere Akhisar, Soma, Salihli ve Turgutlu ilçe merkezleri göç almaktadır. Manisa merkez, son yirmi yıl içerisinde Ege Bölgesinde nüfusu oransal olarak en hızlı artan il merkezi olmuştur. Bu hızlı artış önemli altyapı sorunlarını, konut ihtiyacını da gündeme getirmiştir. Kent şu anda, güneyinde Manisa dağı ve askeri alanlar, kuzeyinde ise verimli tarım arazileri yer aldığından doğuya ve batıya doğru gelişme eğilimleri göstermektedir. Bu nedenle lineer bir gelişme denilebilse bile 1962 yılından bu yana kent imar planı bir bütün olarak alınmadığından kent yakınındaki yerleşimler (Uncubozköy, Keçiliköy, Kuşlubahçe, Nurlupınar, Horozköy mahalleleri) gelişi güzel, ana kentin çekimine kapılarak kendi başlarına büyümüşlerdir (Manisa Belediyesi, 2010: 4).

1/5000 İmar planında gelişme alanı olarak planlanan alanlar; Yeni mahalle, Horozköy, Barbaros mahallesi, Nurlupınar mahallesi, Uncubozköy ve çevresi, Manisa Birlik alanı, Keçiliköy, Karaçay batısı Organize Sanayi Bölgesi gelişme alanı ve kentin gelişme alanı şeklindedir. Yeni mahalle, Horozköy, Barbaros, Nurlupınar, Keçiliköy mahalleleri kaçak yapıların fazla olduğu mahalleler olduğundan gelişme alanları olarak tespit edilmiştir. Uncubozköy ve çevresi ise konut olarak planlanmış olup daha çok kooperatif konutları yapılmaktadır. Manisa Birlik alanı olarak tanımlanan alan "Ucuz Konut Alanı" olarak kabul edilmiştir. Bu alanda da kooperatifler aracılı̆̆ıyla konutlar üretilmektedir. Karaçay batısı Organize Sanayi Bölgesi gelişme alanı olarak ve devamında yeni konut gelişme alanları planlanmıştır. Akıncılar, Alaybey, Anafartalar (1-2), Arda, Çarşı, Dinçer, Ege, İbrahim Çelebi, Kuyualan, Mimar Sinan, Nişancıpaşa, Peker, Sakarya, Saruhan, Tevfikiye, Topçuasım, Tunca, Utku, Yarhasanlar, Laleli, Merkez Efendi, Mesir mahalleleri 1989 Revizyon İmar Planı ile yapılaşmaya açılan ve bugün itibarıyla \% 95 yapılaşmasını tamamlamış yerleşmelerdir (Manisa Belediyesi, 2010: 4).

Adakale, Akgün, Akmescit, Güzelyurt, Keçiliköy, Lalapaşa, Mutlu, Şehitler, Uncubozköy, Yeni, 75. Y1l mahalleleri yapılaşmaları devam etmektedir. Kaynak, Dere, Dilşeker, Göktaşlı, Bayındırlık, Kuşlubahçe, İshakçelebi, Kocatepe mahalleleri şehrin eski yerleşimleri olmalarına rağmen kentin çeşitli etkenlerle göç 
alması nedeniyle çarpık yapılaşmanın (kaçak-gecekondu)olduğu yerlerdir. Adnan Menderes, Akpınar, Atatürk Barbaros, Cumhuriyet, 50. Y11, Fatih, M. Fevzi Çakmak, Gediz, Hafsa Sultan, Kazım Karabekir, Nurlupınar, Turgut Özal mahalleleri ıslah imar planı neticesinde oluşmuş mahallelerdir. Ayrıca Manisa'nın planlı yapılaşmasını sürdürdüğ̈̈ Yeni Manisa 2. Etap gelişme alanının konuta açılma çalışmaları devam etmektedir. Bu bölgede 10500 konut ve 42000 nüfus hedeflenmektedir. Gelecek nüfusun ihtiyaçlarını karşılayacak şekilde kentsel donatılar planlanmıştır (Manisa Belediyesi, 2010:4-5).

\section{MANISA ILIININ YÖNETSEL TARIHCCESİ VE MANISA'DA BELEDIYYECILIIGIIN TARIHII GELİ̧̧iMi}

Manisa ve çevresi, tarihi devirlerde Hititler, Akalar, Frigyalılar, Lidyalılar, Persler, Makedonyalılar, Bergamalılar, Romalılar ve Bizanslılar tarafindan yönetilmiştir. Saruhan Bey, 1313 yılında Manisa'yı Bizanslılardan aldıktan sonra bu şehri beyliğine merkez yapmıştır. Bu tarihten sonra da bu yöreye Saruhan Beyliği adı verilmiş̧ir. 1410 yılında Osmanlı egemenliğine girinceye kadar beylikle yönetilmiştir. 1410 yılından sonra Manisa Şehzade sancağı yapılmıştır. 1437-1595 tarihleri arasında Manisa ve yöresi şehzadeler tarafindan yönetilmiştir. Fatih sultan Mehmet ve Kanuni Sultan Süleyman burada yöneticilik yapmışlardır. III. Mehmet 1595 'te padişah olunca padişah çocuklarının vali olma geleneğini kaldırmıştır ve bu tarihten sonra Manisa'nın yönetimi Anadolu Beylerbeyliği' ne bağlı sancak beylerine bırakılmıştır. 1627 y1lından sonra da arpalık olarak verildiği için mütesellimler ve 1876 yılından sonra mutasarrıflar tarafından idare edilmiştir (Manisa Valiliği, 2000: 64).

Osmanlı İmparatorluğu yönetim bakımından Rumeli ve Anadolu olmak üzere iki eyalete bölünmüştü. Eyaletler sancaklara, sancaklar kazalara ayrılmıştı. Manisa bu yönetim düzeni içinde 1595-1836 tarihleri arasında merkezi Kütahya olan Anadolu Eyaleti’ne bağlı Saruhan Sancağı idi. Sancağın merkezi Manisa, kazaları da 1628'de; Menemen, Foçalar, Güzelcehisar, Gördük, Akhisar, Marmara, Ilıca, Adala, Mendehorya, Borlu, Demirci, Gördes ve Kayacık’tır (Manisa Valiliği, 2000:64).

1831'de Manisa, Saruhan Sancağ1 olarak Anadolu Eyaleti'ne bağlı görünmektedir. 1836 y1lında yapılan idari değişiklikle Aydın eyalet merkezi olunca, Saruhan Sancağı Anadolu Eyaleti’nden alınıp, İzmir ve Menteșe Sancakları ile birlikte Aydın Eyaleti’ne bağlanmıştır. Saruhan Sancağı XVII. yüzyıldaki ilçelerini XIX. yüzyılın yarısına kadar bazı değişiklikle korumuştur. 1845'deki yönetsel bölünmede Saruhan Sancağı, Aydın Eyaleti'nden alınarak Saruhan Eyaleti olmuştur. Bu dönemde Saruhan Eyaleti'nin; Merkez Sancak, Karesi (Balıkesir), Ayvalık ve Sığla (İzmir) olmak üzere dört sancağı vardı. 1847 yılında Saruhan yeniden Aydın Eyaleti’ne bağlanmıştır. 1850-1851 yılında Aydın Valisi Halil Paşa eyalet merkezini Aydın'dan İzmir'e kaldırmıştır. Bu tarihten sonra eyalet merkezi İzmir olmuştur (Manisa Valiliği, 2007: 89). 1867 Vilayet Nizamnamesi ile eyalet sistemi kaldırılarak, vilayet sistemine geçilmiştir. Bu yönetsel düzenlemelerde Saruhan Sancağı, Aydın Vilayeti sınırları içinde idi (Manisa Valiliği, 2000: 64).

1867 Vilayet Nizamnamesi'nden sonraki düzenlemeyi gösteren ve 1878 yılı bilgilerini içeren ilk Aydın Salnamesi’ ne göre Saruhan Sancă̆ı; Manisa, Alaşehir, Akhisar, Demirci, Gördes, Kırkağaç, Salihli, Turgutlu, Eşme, Kula ve Bergama kazalarından oluşmaktadır. Ancak 1883 yılı bilgilerini içeren salnamede Bergama’nın yerini Soma almıştır. Saruhan Sancă̆ı' nın 1890 yılında 11 kazada, 19 nahiyesi ve toplam 985 köyü vardı. 1908 yılında ise 11 kazada, 19 nahiyesi ve toplam 1094 mahalle ve köyü vardı (TC. Manisa Valiliği, 2000:64). Ulusal Kurtuluş Savaşı evresinde, 15 Mayıs 1919'da başlayan Yunan işgali sırasında Aydın Vilayeti' ne bağlı sancakların bağımsız birer liva durumuna getirilmesine ilişkin girişimden bir sonuç alınmamasına karşın, merkezi Akhisar olmak üzere Saruhan Sancağı bağımsız bir statü kazanmıştır.

TBMM'nin 13 Mayıs 1920 tarihli oturumunda, Akhisar ve Kırkağaç kazaları ile İzmir'in Bergama kazasının Karesi livasına bağlanması önerisi komisyona havale edilmiştir (Manisa Valiliği, 2007: 92). Ankara Hükümeti’nin yazışmalarında mutasarrıflık merkezi olarak Alaşehir muhatap alınmıştır. Öte yandan İstanbul Hükümeti'nin de bu konuda düzenleme girişimi olmuştur. Demirci, Gördes, Kula, Salihli, Alaşehir kazalarını kapsayan "Alaşehir Sancağı" altında sancak oluşturulması, bölgenin Yunan işgali altında bulunmasının yarattığı güçlükten dolayı gerçekleşmemiştir. 20 Ocak 1921 tarihli Teşkilat-1 Esasiye Kanunu'nda devletin taşra örgütlenmesinin vilayet, kaza, nahiye ve köylerden oluştuğu belirtilmekteydi. Buna göre sancak/liva örgütü ortadan kalkmış görünmekle beraber, 1924 Anayasası'nın uygulanmasına 
kadar varlığını korumuştur (Manisa Valiliği, 2007: 93). 1922 yılına kadar Aydın vilayetine bağlı kalan Saruhan Sancağı, Kurtuluş’tan sonra "bağımsız bir sancak" yapılmıştır. 1923'te mutasarrıflıkların vilayet sayılması üzerine Saruhan Sancağı' da vilayet olmuştur. 1924 Anayasası Türkiye'nin coğrafi ve ekonomik şartlara göre illere, illerin ilçelere ve ilçelerinde bucaklara bölüneceği hükmünü getirmiştir (Manisa Valiliği, 2007: 93).

24.10.1926 tarih ve 4248 sayılı kararname ile haberleşme ve işlemlerde kolaylık sağlanması açısından Saruhan ilinin adı Manisa olarak değiştirilmiştir (Manisa Valiliği, 2000: 64). Bu çerçevede 1929 tarihli Vilayet İdaresi Kanunu ve 1949 yılında 5442 sayılı İl idaresi Kanunu yürürlüğe girmiştir. 1924 Anayasası'nın yürürlükten kalkması üzerine, halkoyuna sunulan 1961 Anayasası'nın merkezi idarenin kuruluşuna ilişkin maddesi, 1982 Anayasası'nda da aynen benimsenmiştir. "Türkiye, merkezi idare kuruluşu bakımından, coğrafya durumuna, ekonomik şartlara ve kamu hizmetlerinin gereklerine göre, illere; illerde diğer kademeli bölümlere ayrılır" ifadesi yenilenmiştir (Manisa Valiliği, 2007: 93).

Manisa ili yönetim yapısı Cumhuriyet'in başından 1953'e kadar korunmuştur. Manisa ilini; Merkez ilçe, Akhisar, Alaşehir, Demirci, Eşme, Gördes, Kırkağaç, Kula, Salihli, Soma, Turgutlu, ilçeleri oluşturmaktaydi. 1953 yılında Uşak il yapılınca Eşme buraya bağlanmıştır. Öncesinde bucak iken Selendi (1954), İnegöl adı kaldırılarak Sarıgöl (1957), Saruhanlı (1959), Ahmetli (1987), Marmara adı kaldırılarak Gölmarmara (1987), Köprübaşı (1990) ilçe yapılarak Manisa ilinin diğer ilçeleri arasında yer almıştır (Manisa Valiliği, 2007: 93).

Manisa Belediyesine ait ilk belgeleri 1878 (1296) yılında yayınlanan Aydın Vilayeti Salnamesi'nin birinci cildinde bulunmaktadır (Manisa Belediyesi, 1977: 15). Salname' nin 116. sayfasinda "BELEDIYE MECLİSI" başlığı altında şu bilgiler verilmektedir:

\section{Reis: Hacı İsmail Hakkı Efendi}

Aza (Belediye Meclisi Üyeleri): Mehmet Şevki Efendi, Bekir Ağa, Şerif Ağa, Hacı Arif Efendi, Hacı İbrahim Efendi, Hacı Mehmet Efendi, Hacı Mehmet Ağa, İzzet Efendi, Ömer Efendi, Andon Efendi, Hayim Efendi, Kolağası Kamil Efendi, Baş Katip İbrahim Efendi, Ser Komiser Hafız Mustafa Efendi, Abdullah Ağa, Halim Ağa.

Belediye Memurları: Sandık Emini Abdülkadir Efendi, Matbaa Memuru Mustafa Efendi, Tabib Janvilako Efendi (Manisa Belediyesi, 1984: 17).

Manisa hakkında da şu bilgiler yer almaktadır: Manisa'da iki minareli Sultan ve Muradiye namıla iki adet selatin, büyük ve küçük minareli 34 cami, 51 mescit, 17 dershane, 2 imaret, 8 tekke, 15 medrese, 1 rüştiye mektebi, 25 sıbyan mektebi, 4 hastane, 1 tımarhane, 4 kütüphane, 69 sebil, 2 şadırvan, 12 küçük tahta köprü, 1 kışla, bağlı köyleriyle beraber 12.333 hanede 27.999 nüfus, 1534 dükkan, 114 mağaza, 10 hamam, 197 çeşme, 55 kahvehane, 14 tütün fabrikası, 64 firın vardır. Manisa alacası isimli meşhur beyaz bezini dokuyan 500 tezgah olup senevi 50 bin top ihraç edilmektedir. Şehrin güneydoğusunda ve 2 saat mesafede üstü açık, suyu 1lık bir de 1lıca vardır (Manisa Belediyesi, 1977: 15).

1908 yılında son defa yayınlanan Aydın Vilayeti Salnamesi'ndeki bilgilerinden sonra cumhuriyete kadar olan döneme ait bilgiler yoktur. 1908 tarihli Aydın Vilayeti Salnamesi' ne göre Manisa'nın 56 mahallesi vardır. Nüfusu ise 17.163'ü kadın, 17.848'i erkek olmak üzere 35.011'dir. 8.895 ev, 1.966 dükkan, 32 han, 9 hamam, 75 un değirmeni, 153 mağaza, 61 firın, 100 kahvehane, 52 meyhane, 5 un ve pamuk fabrikası bulunmaktadır (Manisa Belediyesi, 1977: 18). Belediye'nin senelik geliri 548.328 kuruştur. Bu gelirin 41.300 kuruşu belediye malı olan taşınmaz malların kiralarındandır. 1903-1904 senelerinde yeni yapılan tekel idaresi, iki kira evi, 20 sene evvel yapılmış olan ve sonradan yeniletilen belediye kıraathanesi, 1903 senesinde düzenlenerek çiçekler yemyeşil çam ve akasya vb. hoş ve gölge eden ağaçlar ve birçok lüks lambaları ile donatılmış olan halka açık belediye bahçesi, belediye binası ve eczanesi belediye tarafindan yaptırılmıştır. Hamidiye bahçesi adı verilen belediye bahçesinin bir tarafına yeni hükümet konağı yapılmaya başlanmıştır (Şimdiki hükümet konağının olduğu yerdedir. Bu konak 6-7 Eylül 1922 yangınında yanmıştır). Bahçenin ortasında padişahın turası ile süslü bir anıt dikilmiştir. Yine bu civarda bulunan gönül alıcı kasr üzerine konulmuş bulunan ve 1906 yılında padişahın tahta çıkışının yıldönümünde açılış töreni yapılan 
büyük çalar saat kulesi, çarşı ve saraçhane seçmeleri de belediye tarafından yaptırılmıştır (Manisa Belediyesi, 1977: 18).

Çarş1 içinde 1903-1904 senelerinde çeşitli yerlerden istasyona giden toplam 23.850 metrekare şose yapıldığ 1 ve tamir edildiği, belediye dairesi önündeki 101 metrekare yere kesme taş döşendiği ve belediye bahçesine konulanlardan başka şehrin uygun yerlerine 1500 mum kuvvetinde 5 adet lüks lambası konulduğu belirtilmektedir. Hatuniye Camii ile çarşı ve belediye bahçesi bitişiğindeki arsa ile kıraathane arasındaki başka başka caddelerin de açılması kararlaştırılmıştır. 1908 tarihli Aydın Vilayeti Salnamesi'nden anlaşılacağı üzere belediye genellikle şehir içinden geçen dereler üzerine köprü yapmak, derelerin sellerini önlemek için duvar yapmak, cadde ve sokakları aydınlatmak için devrin şartlarına göre fener ve lüks lambası koymak, lağım döşemek, cadde ve sokaklara kaldırım döşemek gibi kamu yararına işler yapmaya çalışmıştır (Manisa Belediyesi, 1977: 18).

\section{6360 SAYILI YASA’NIN ÖNCESINDE VE SONRASINDA MANISA}

6360 sayı1ı 13 İlde Büyükşehir Belediyesi ve 26 İlçe Kurulması ile Bazı Kanun ve Kanun Hükmünde Kararnamelerde Değişiklik Yapılmasına Dair Kanun 12 Kasım 2012 tarihinde TBMM'de kabul edilmiştir. 11. Cumhurbaşkanı Abdullah Gül tarafından 5 Aralık 2012 tarihinde imzalanmıştır ve 6 Aralık 2012 tarihli 28489 sayılı Resmi Gazete' de yayımlanarak 30 Mart 2014 tarihinde yürürlüğe girmiştir. 6360 sayılı yasa ile Aydın, Balıkesir, Denizli, Hatay, K. Maraş, Mardin, Malatya, Manisa, Muğla, Tekirdağ, Trabzon, Şanlıurfa ve Van illerinin belediyeleri 30 Mart 2014 tarihinde büyükşehir belediyesi statüsüne kavuşmuştur.

Daha sonradan Ordu ilinin nüfusunun 750.000'i aşması üzerine 6447 sayılı yasa ile 6360 sayılı yasaya ilave yapılarak bu yasanın Ordu ili içinde geçerli olması sağlanmıştır (Çelik ve Altıparmak, 2013: 19). 6447 sayılı 13 On Üç İlde Büyükşehir Belediyesi ve Yirmi Altı İlçe Kurulması İle Bazı Kanun ve Kanun Hükmünde Kararnamelerde Değişiklik Yapılmasına Dair Kanun'da Değişiklik Yapılması Hakkında Kanun 14.03,2013 tarihinde TBMM'de kabul edilmiştir. 22 Mart 2013 tarihli 28595 sayılı Resmi Gazete' de yayımlanmıştır.

Genel hatlarıyla 6360 sayılı yasa ile nüfusu 750.000 'in üzerinde olan iller büyükşehir belediyesine dönüştürülmüştür, büyükşehir belediyelerinin sınırları il sınırları olmuştur, büyükşehirlerdeki il özel idareleri kaldırılmıştır. Belde belediyelerinin ve köylerin (orman köyleri dahil) tüzel kişilikleri kaldırılarak mahalleye dönüştürülmüştür. Büyükșehir belediyesi bulunan yerlerde ayrılma yoluyla yeni bir belde kurulmasında, yeni kurulacak belde için aranan 50.000'lik nüfus kriteri, 20.000'e düşürülmüştür. Belediye sınırları içinde nüfusu 500 'ün altında mahalle kurulamayacaktır.

Büyükşehir kapsamındaki belediyeler arasında hizmetlerin yerine getirilmesi bakımından uyum ve koordinasyon, büyükşehir belediyesi tarafından sağlanacaktır. Valiliklere bağlı olarak Yatırım İzleme Koordinasyon Kurulu Başkanlıkları kurulmaya başlanmıştır (Ökmen ve Parlak 2013:314). 6360 Sayılı Yasa'nın yürürlüğe girmesiyle birlikte büyükşehir belediye sayısı 16'dan 30'a, büyükşehir ilçe belediyesi sayısı ise 143 'ten 519'a çıkmıştır. İl belediye sayısı 65'den 51'e, ilçe belediye sayısı 749'dan 400'e, belde belediye sayıs1 1.977 'den 396'ya düşmüştür. Toplamda ise belediye sayısı 2.950 'den 1396 'ya düşmüştür. İl özel idarelerinin sayıs1 81 'den 51'e, köy sayısı da 34.283'den 17.720 'ye düşmüştür (Çelik ve Altıparmak, 2013: 220).

6360 say1lı yasa yürürlüğe girmeden önce Manisa ilinde mülki yönetim birimi olarak merkez dahil 16 ilçe, 68 belde, 648 tanesi orman köyü olmak üzere 780 köy bulunmaktaydı (Çelik ve Altıparmak, 2013:219). Ahmetli ve Gölmarmara bucakları ilçe statüsünü 1987 yılında kazanmış, Köprübaşı ise 1990 yılında ilçe olmuştur. Diğer ilçeler ise Cumhuriyet öncesinin kazalarıdır. Manisa'da yerel yönetim birimi olarak 1'i il, 15 ilçe, 68'i kasaba (belde) olmak üzere toplam 84 belediye bulunmaktaydı (Manisa Valiliği, 2007: 95). Manisa, belediye sayısı bakımından Türkiye'de en fazla belediyeye sahip 5. il, köy sayısı bakımından ise en fazla köye sahip 8. il konumunda idi. 


\section{MANISA İLINNDEKI YERLEŞIMM BİRİMLERİNİN İLÇELERE DAĞILIMI}

\begin{tabular}{|c|c|c|c|c|}
\hline İlceler & Belediye Sayısı & Köy Sayısı & Köy Bağlısı Sayısı(*) & Mahalle Sayısı \\
\hline TOPLAM & 17 & - & - & 1088 \\
\hline Şehzadeler & 1 & - & - & 65 \\
\hline Yunus Emre & 1 & - & - & 89 \\
\hline Ahmetli & 1 & - & - & 23 \\
\hline Akhisar & 1 & - & - & 109 \\
\hline Alaşehir & 1 & - & - & 87 \\
\hline Demirci & 1 & - & - & 101 \\
\hline Gölmarnıara & 1 & - & - & 21 \\
\hline Gördes & 1 & - & - & 63 \\
\hline Kırkağaç & 1 & - & - & 47 \\
\hline Köprüibaşı & 1 & - & - & 46 \\
\hline Kula & 1 & - & - & 60 \\
\hline Salihli & 1 & - & - & 103 \\
\hline Sarıgöl & 1 & - & - & 35 \\
\hline Saruhanlı & 1 & - & - & 50 \\
\hline Selendi & 1 & - & - & 57 \\
\hline Soma & 1 & - & - & 71 \\
\hline Turgutlu & 1 & - & - & 61 \\
\hline
\end{tabular}

Yukarıdaki tablodan anlaşılacağı üzere Manisa ilinde 17 adet ilçe bulunmaktadır. Bunlar: Ahmetli, Akhisar, Alaşehir, Demirci, Gölmarmara, Gördes, Kırkağaç, Köprübaşı, Kula, Salihli, Sarıgöl, Saruhanlı, Selendi, Soma, Şehzadeler, Turgutlu ve Yunusemre'dir. 6360 sayılı Kanunla Manisa'da, Merkez ilçe; köy, mahalle ve beldeleri ile birlikte ikiye bölünerek Şehzadeler ve Yunusemre adiyla iki yeni ilçe oluşturulmuştur. 8 Eylül Caddesinin (Ayn-1 Ali'nin bulunduğu caddenin) doğusunda yer alan mahalle, köy ve beldeleri içine alan ilçenin adı Şehzadeler' dir. Şehzadeler' in 65 Mahallesi (mevcut mahalleler ve tüzel kişiliği sona eren belde ve köylerle birlikte) vardır. Batısında kalan mahalle, köy ve beldeleri içine alan ilçenin adı Yunusemre' dir. Yunusemre ilçesinin 89 Mahallesi (mevcut mahalleler ve tüzel kişiliği sona eren belde ve köylerle birlikte) vardır.

Yine kanunla Demirci ilçesine bağlı; Borlu Belediyesi ile Kulalı, Selviler, Saraycık, Yabac1, Tokmaklı, Karyağdı, Gökveliler, Armağan, Çayköy, Yumuklar ve Yenice köyleri Köprübaşı ilçesine bağlanmıştır.

Tüzel kişiliği kaldırılan belde belediyeleri şunlardır: Çobanisa, Hacıaliler, Hamzabeyli, Karaağaçlı, Karaoğlanlı, Muradiye, Sancaklı, Bozköy, Sancaklı İğdecik, Selimşahlar, Üçpınar, Yağcılar, Yeniköy (Merkez); Gökkaya (Ahmetli); Akselendi, Ballıca, Beyoba, Dağdere, Kayalığlu, Mecidiye, Medar, Süleymanl1, Zeytinliova (Akhisar); Kavaklıdere, Kemaliye, Killik, Piyadeler, Uluderbent, Yeşilyurt (Alaşehir); Borlu, Durhasan, İcikler, Mahmutlar (Demirci); Çiçekli, Güneşli, Kayacık (Gördes); Bakır, Gelenbe, İlyaslar, Karakurt (Kırkağaç); Gökçeören, Sandal (Kula); Adala, Durasallı, Gökeyüp, Mersinli, Poyrazdamlar, Sart, Taytan, Yılmaz (Salihli); Alibeyi, Büyükbelen, Dilek, Gökçeköy, Gümülceli, Hacırahmanl1, Halitpaşa, İshakçelebi, Koldere, Kumyukcak, Mütevelli, Nuriye, Paşaköy (Saruhanlı); Avdal, Cenyeri, Turgutalp, Yağc1llı (Soma); Urganlı, Derbent (Turgutlu).

68 beldedeki belediye başkanının 2009 yerel seçimlerine göre partilere dağılımı ise; AKP 30, CHP 13, MHP 11, DP 9, DSP 4, BTP 1 şeklindeydi. 30 Mart 2014 yerel seçimlerinde ise Manisa Büyükşehir Belediye Başkanlığı'nı MHP'li mevcut belediye başkanı tekrar kazanmıştır. 11 ilçede belediye başkanlığını (Ahmetli, Akhisar, Gölmarmara, Gördes, Kırkağaç, Köprübaşı, Saruhanl1, Soma, Şehzadeler, Turgutlu, Yunusemre) AKP'li adaylar, 6 ilçede belediye başkanlığını (Alaşehir, Demirci, Kula, Sarıgöl, Salihli, Selendi) MHP'li adaylar kazanmıştır. Büyükşehir Belediye Meclisi'nde ise AKP'den 46, MHP'den 35, CHP'den 7 meclis üyesi yer almaktadır 
Manisa İli ve İlçeleri Toplam Nüfusları

\begin{tabular}{|c|c|c|c|c|c|c|c|c|c|}
\hline \multirow[b]{2}{*}{ İlçe Adı } & \multicolumn{2}{|c|}{$\begin{array}{r}\text { Nüfus } \\
\text { Artış Hızı }\end{array}$} & \multicolumn{2}{|c|}{$\begin{array}{r}\text { Nüfus } \\
\text { Artış Hızı }\end{array}$} & \multicolumn{2}{|c|}{ Nüifus Artış } & \multicolumn{3}{|c|}{$\begin{array}{r}\text { Nüfus } \\
\text { Artış Hızı }\end{array}$} \\
\hline & 2009 & $\%$ & 2010 & $\%$ & 2011 & Hizı \%o & 2012 & $\% 0$ & 2013 \\
\hline Manisa & 1331957 & 35,1 & 1379484 & $-29,0$ & 1340074 & 4,5 & 1346162 & 9,8 & 1359463 \\
\hline Merkez & 340466 & 68,3 & 364547 & $-42,9$ & 349236 & 21,2 & 356702 & 21,2 & 364332 \\
\hline Şehzadeler & - & - & - & - & 159622 & 15,7 & 162143 & 15,3 & 164649 \\
\hline Yunusemre & - & - & - & - & 189614 & 25,7 & 194559 & 26,0 & 199683 \\
\hline Ahmetli & 16037 & $-14,8$ & 15801 & 35,6 & 16373 & 7,3 & 16493 & $-13,9$ & 16266 \\
\hline Akhisar & 158857 & $-1,5$ & 158614 & 6,5 & 159650 & 6,1 & 160620 & 8,0 & 161918 \\
\hline Alaşehir & 99851 & 56,4 & 105644 & $-63,8$ & 99110 & 0,4 & 99145 & 3,6 & 99504 \\
\hline Demirci & 50533 & $-1,6$ & 50454 & $-17,8$ & 49562 & $-10,6$ & 49041 & $-117,0$ & 43628 \\
\hline Gölmarmara & 15993 & $-9,8$ & 15837 & $-5,6$ & 15749 & $-8,9$ & 15609 & $-10,3$ & 15449 \\
\hline Gördes & 32070 & $-22,9$ & 31345 & $-15,7$ & 30857 & $-11,9$ & 30491 & $-4,9$ & 30341 \\
\hline Kırkağaç & 47148 & 329,4 & 65542 & $-329,0$ & 47165 & $-47,2$ & 44991 & 25,7 & 46160 \\
\hline Köprübaşı & 9830 & 4,2 & 9871 & 3,6 & 9907 & 7,4 & 9981 & 341,6 & 14045 \\
\hline Kula & 47521 & $-9,6$ & 47065 & $-0,7$ & 47030 & $-12,8$ & 46433 & $-11,7$ & 45892 \\
\hline Salihli & 155333 & 3,3 & 155841 & $-2,5$ & 155446 & $-1,0$ & 155291 & 6,7 & 156330 \\
\hline Sarıgöl & 36179 & 1,5 & 36234 & 3,6 & 36366 & $-5,2$ & 36179 & 0,8 & 36209 \\
\hline Saruhanlı & 56584 & $-21,4$ & 55386 & $-19,0$ & 54343 & $-3,4$ & 54160 & $-6,3$ & 53821 \\
\hline Selendi & 23791 & $-28,7$ & 23117 & $-20,5$ & 22648 & $-16,7$ & 22.273 & $-10,2$ & 22047 \\
\hline Soma & 101011 & 11,9 & 102224 & 4,1 & 102642 & 0,2 & 102666 & 26,2 & 105391 \\
\hline Turgutlu & 140753 & 8,6 & 141962 & 14,2 & 143990 & 14,5 & 146087 & 13,9 & 148130 \\
\hline
\end{tabular}

Kaynak: TÜIKK, ADNKS Sonuçları

Yukarıdaki tablodan anlaşılacağı üzere, 2013 yılı Adrese Dayalı Nüfus Kayıt Sistemi (ADNKS) sonuçlarına göre 1.359.463 kişidir. Manisa merkez nüfusu 364.332'dir (Şehzadeler ve Yunusemre ilçeleri hariçtir). İlin nüfus yoğunluğu ise $\mathrm{km}^{2}$ başına 104 kişidir. Manisa'nın nüfus bakımından en büyük beş ilçesi sirasiyla Yunusemre (199.683), Şehzadeler (164.649), Akhisar (161.918), Salihli (156.330) ve Turgutlu'dur (148.130). Nüfus bakımından en küçük ilçesi ise Köprübaşı'dır (14.045). Manisa ilinin nüfusu, 2012 Adrese Dayalı Nüfus Kayıt Sistemi sonuçlarına göre ise 1.346.162 kişidir. Nüfusun 904.513 kişisi şehirlerde yaşarken, 441.649 kişisi belde ve köylerde yaşamaktadır. Şehirde yaşayanların oranı \%67.19, köyde yaşayanların oranı \% 32.81'dir. 2012 verilerine göre il merkezi nüfusu 356.702'dir.

6360 sayılı kanunla tesis edilen Manisa Büyükşehir Belediyesi, sahip olduğu hukuki, idari, mali vb. statü gereği, mahalli müşterek nitelikteki birtakım hizmetlerin üretilmesi, organizasyonu ve sunulması konusunda önemli görev, yetki ve sorumluluklarla karşı karşıya kalmıştır. Sözü edilen kanunla getirilen örgütlenme ve 5216 sayılı Büyükşehir Belediyesi Kanununun yanında ilgili diğer mevzuat çerçevesinde Manisa Büyükşehir Belediyesi büyükşehir sınırları içerisinde altyapıdan ulaşıma imardan çevreye kadar geniş bir yelpazede çok önemli yetkilerle donatılmış, yepyeni görev ve sorumluluklarla donatılmıştır (Ökmen ve diğerleri, 2014: 93).

Bu çerçevede büyükşehir ve ilçe belediyelerinin görev, yetki ve sorumlulukları 5216 say1l kanunun 7. maddesinde ayrıntılı bir biçimde düzenlenmiştir. Özellikle altyapı, ulaşım, imar gibi büyükşehir belediye sınırlarında bütüncül bir düzenleme ve uygulama yapabilmeyi gerekli kılan görev ve yetkiler büyükşehir belediyesinin uhdesine verilmiştir. İlçe belediyeleri ise daha çok büyükşehir sisteminin bütüncül yapısı içerisinde ikincil derecedeki ve daha yerel nitelikteki hizmetleri görmek üzere yetkilendirilmiştir. Yasadaki genel eğilimin büyükşsehir belediyesinin genel ve birincil yetkilerle güçlendirilmesi olduğu söylenebilir (Ökmen ve diğerleri, 2014: 93).

6360 sayılı Kanunla, büyükşehir belediyeleri ile büyükşehir ilçe belediyelerinin genel bütçe vergi gelirlerinden aldığı paylar oransal olarak artmaktadır. Bu oran büyükşehir ilçe belediyeleri için \% 2,50'den $\%$ 4,50'ye çıkarılırken, büyükşehir belediyeleri için \%5'ten \% 6'ya çıkarılmaktadır. Bunun dışında da bazı kalemlerde büyükşsehir belediyelerinin gelirlerinin artacağını söylemek mümkündür. Genel bütçe vergi paylarının dağıtım oranlarının değişmesi yanında, dağıtım esaslarında da değişikliğe gidilmiştir. Nüfusun belirleyiciliğinin yanına yüzölçümü faktörü de eklenerek daha adil bir dağıtım hedeflendiği anlaşılmaktadır.

6360 sayılı kanunun getirdiği yeni büyükşehir sistemi diğer konularda olduğu gibi mali açıdan da bazı sonuçlar ortaya koymuştur. Bu sonuçların Manisa Büyükşehir Belediyesi özelinde ortaya koyacağı bazı 
sonuçlar aşağıdaki tabloda irdelenmiştir. Buna göre Manisa ilinde tüm belediyelerin ve özel idarenin genel bütçe vergi gelirlerinden 2011 yılında aldığı pay 314.847.414 TL iken ve genel bütçe vergi gelirlerinden kişi başına düşen miktar 234 TL iken, 6360 Sayılı Yasa'nın yürürlüğe girmesinden sonra Manisa ilinde tüm belediyelerin genel bütçe vergi gelirlerinden aldığı pay 471.804.118 TL'ye ve genel bütçe vergi gelirlerinden kişi başına düşen miktar da 350 TL'ye çıkacaktır. Manisa ilinin büyükşehir statüsüne kavuşmasıyla genel bütçe vergi gelirlerinden alacağı pay \% 67 oranında artış gösterecektir.

\begin{tabular}{|c|c|c|c|c|c|c|}
\hline \multicolumn{7}{|c|}{$\begin{array}{l}\text { BELEDIYYE GELIRLERI NE KADAR ARTACAK ? } \\
\text { NEL BÜTÇE VERGI GELIRLERINDEN NE KADAR ALACAK? }\end{array}$} \\
\hline \multicolumn{7}{|c|}{ 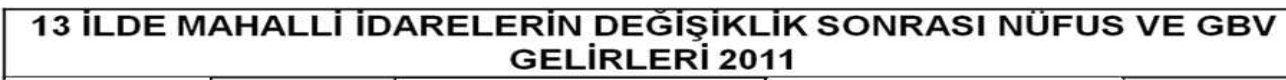 } \\
\hline \multirow[b]{2}{*}{ iLi } & \multirow[b]{2}{*}{$\begin{array}{c}\text { NÜFUS } \\
\text { (TÜM IL SINIRI) }\end{array}$} & \multicolumn{2}{|c|}{ MEVCUT } & \multicolumn{2}{|c|}{ KANUN SONRASI } & \multirow{2}{*}{$\underset{\%}{\text { ARTIŞORANI }}$} \\
\hline & & $\begin{array}{c}\text { TÜM } \\
\text { BELEDIYELER+ } \\
\text { ÖZEL IDARELERIN } \\
\text { TAHAKKUKUU }\end{array}$ & $\begin{array}{c}\text { Kisi BASI } \\
\text { (TL) }\end{array}$ & $\begin{array}{l}\text { TÜM } \\
\text { BELEDIYELER } \\
\text { TAHAKKUKU }\end{array}$ & $\begin{array}{l}\text { Kiși BASI } \\
\text { \{TL\}) }\end{array}$ & \\
\hline AYDIN & 1.006 .541 & 209.339 .652 & 208 & 319.343 .214 & 317 & 66 \\
\hline BALIKESIR & 1.160 .731 & 237.341 .045 & 204 & 416.642 .542 & 359 & 57 \\
\hline DENIZLI & 950.507 & 214.939 .359 & 226 & 330.431 .308 & 348 & 65 \\
\hline HATAY & 1.483 .674 & 326.543 .127 & 220 & 498.616.381 & 336 & 65 \\
\hline K.MARAS & 1.063 .174 & 250.410 .392 & 236 & 369.001 .284 & 347 & 68 \\
\hline MALATYA & 762.366 & 183.458.624 & 241 & 274.921.889 & 361 & 67 \\
\hline MARDIN & 773.026 & 198.318 .948 & 257 & 270.584 .201 & 350 & 73 \\
\hline MANISA & 1.346 .162 & 314.847 .414 & 234 & 471.804.118 & 350 & 67 \\
\hline MUGLA & 851.145 & 158.541 .251 & 186 & 330.048 .702 & 388 & 48 \\
\hline Ş.URFA & 1.762 .075 & 371.598 .836 & 211 & 543.517 .480 & 308 & 68 \\
\hline TEKIRDAG & 852.321 & 178.186 .771 & 209 & 324.233 .985 & 380 & 55 \\
\hline TRABZON & 757.898 & 178.434 .363 & 235 & 245.436 .993 & 324 & 73 \\
\hline VAN & 1.051 .975 & 214.763 .843 & 204 & 387.319 .092 & 368 & 55 \\
\hline TOPLAM & 13.821.595 & 3.036 .723 .623 & & 4.781 .901 .189 & & \\
\hline
\end{tabular}

Büyükşehirler dışındaki, il ve ilçe belediyeleri ile il özel idarelerinin genel bütçe vergi gelirlerinden aldıkları pay oranları azalmış gibi görünse de; sayıları ve nüfusları azalacağından genel bütçe vergi gelirlerinden alacakları kişi başı pay miktarlarında artış olmaktadır. Dolayısıyla, yerel yönetimler genel anlamda mali açıdan güçlendirilmektedir (Ökmen ve diğerleri, 2014: 91).

İl sınırında büyükşehir modelinin yerel yönetim sisteminde ölçek optimizasyonuna yönelik bir yeniden yapılandırma girişimi olduğu anlaşılmaktadır. Bu değişiklikle, bir yandan merkezden sunulması optimal olmayan kamu hizmetleri yerel yönetimlere devredilirken, diğer yandan optimal ölçeğin altında olmaları nedeniyle bazı yerel yönetim birimleri kapatılarak ve/veya birleştirilerek yerel yönetimlerde optimal ölçek düzeyine ulaşılması hedeflenmektedir.

\section{SONUÇ VE ÖNERILER}

İl sınırlarında büyükşsehir modeline geçişle birlikte, Manisa Büyükşehir Belediyesi ilçelere bir takım beledi hizmetler götürecektir. Manisa'ya en uzak ilçeler sırasıyla Demirci (158 km.), Selendi (155 km.), Sarıgöl (128 km.), Köprübaşı (123 km.), Alaşehir'dir (109 km.). Bu ilçelerin mahalleye dönüşen köylerini ve orman köylerini de düşünürsek buralara etkin ve verimli hizmet götürmek ve hizmette aksamalara mahal vermemek için il genelinde emlak, istimlak hizmet ve uygulamalarında da yönetim, planlama ve koordinasyon açısından etkinlik sağlayıcı çalışmalar yapılmalıdır.

$\mathrm{Bu}$ çalışma çerçevesinde, il genelinde kamuya ait birçok tesisin yıllardır süregelen mülkiyet sorunları çözüme ulaştırılabilir, kamulaştırmaları tamamlanmış, kullanım ve işletilmeleri önündeki hukuki sakıncaların önüne geçilebilir. Bu durum Büyükşehir Belediyesi’nin hizmetlerde tasarruf, etkinlik ve verimlilik yönünde önemli bir atılmasını sağlayacaktır (Ökmen ve diğerleri, 2014:99). Manisa il sınırlarının tamamında kapsamlı bir numarataj çalışması planlanmalı, sokak ve cadde isimleri ile kapı numaraları uygulamaları yapılarak yenilenmeli ve standardize edilmelidir.

5216 ve 6360 sayılı kanunlar; ulaşım, toplu taşıma ve altyapı hizmetleri konusunda bütün yetkiyi büyükşehir belediyesine vermektedir. Dolayısıyla, il sınırında büyükşehir belediye modeline geçildikten 
sonra Manisa'da daha bütüncül, planl1, etkin ve verimli bir ulaşım sistemi organize edilebilir. Bu bağlamda, hem karayolu hem hafif raylı sistemler başta olmak üzere demiryolu ulaşımı il düzeyinde yeniden örgütlenmeli ve güncellenmelidir. Manisa Büyükşehir Belediyesi’ne vatandaşlardan, kamu idarelerinden, özel sektörden, üniversite ve sivil toplum kuruluşlarından gelen talepler, bütüncül ve optimal bir yaklaşımlar analiz edilmeli ve orta ve uzun vadeli projeksiyonlar oluşturulmalıdır. Burada söz konusu modele geçişle birlikte yeni oluşan bölgelerin- yerleşim alanlarının toplu taşıma ihtiyaçları birlikte değerlendirilerek, sadece belli bir bölge veya odağa yönelik değil, tüm ili ve ulaşımın tüm paydaşlarını kapsayacak şekilde bütüncül çözümler üretilmeye çalışılmalıdır. Üniversite, odalar ve sivil toplum kuruluşlarının bu bağlamdaki destekleri ve katkıları mutlaka alınmalıdır (Ökmen ve diğerleri, 2014:99-100).

$\mathrm{Bu}$ çerçevede örneğin, Manisa'nın tamamında aynı mesafedeki taşıma ücretleri tek tip hale getirilerek, hem vatandaşın hem de esnafin memnun olacağı makul ve standart bir fiyat tarifesi oluşturulabilir. Manisa'daki tüm toplu taşıma araçlarının kalkış ve varış noktaları, gidiş ve dönüş güzergahları ile güzergah üzerindeki tüm duraklar net olarak belirlenerek güzergah ihlalleri ve toplu taşıma esnafının karşı karşıya gelmesi gibi sorunlar asgariye indirilerek çalışma barışı ve huzuru sağlanmalıdır.

Manisa Büyükşehir Belediyesi bünyesinde tüm il sınırlarını kapsayacak şekilde ulaşım ana planı ve lojistik ana planı çalışmaları yapılmalıdır. Ulaşım ana planı çerçevesinde, Manisa içerisinde günlük olarak yapılan bütün yolculuklar modellenerek, belli sayıda trafik zonu oluşturulmalı ve bu çerçevede yol ağları, otopark alanları, transfer merkezleri, dolaşım planları, bisiklet yolları gibi ulaşım ile ilgili birçok konu bütüncül olarak ele alınmalıdır.

İl sınırında büyükşehir belediye modeline geçişle birlikte, herhangi bir il veya ilçe belediyesinin kendi imkanlarıyla tek başına yapamayacağı ölçekte çok sayıda yol, cadde, sokak, köprülü kavşak ve battı-çıktı gibi ulaşım altyapı projeleri daha kolay bir şekilde hayata geçirilebilecektir. Bu şekilde; şehir aydınlatmada da daha verimli, etkin, planlı, standart, modern ve düzenli hizmetlerin yürütülebileceği değerlendirilmektedir.

İl sınırında büyükşehir belediyesi olunmasıyla birlikte ilçe belediyeleri tarafindan işletilen şehirlerarası otobüs terminalleri, yapılacak protokoller çerçevesinde personel, malzeme, yapı ve arsalarıyla birlikte Büyükşehir Belediyesi'ne devredilmiş olacaktır. Terminallerde etkin ve sürekli denetim sağlanması amacıyla terminal ihtisas zabıta birimi oluşturularak, kapalı devre güvenlik kamera sistemi kurulup iç ve dış emniyet ve kontrol sağlanabilir.

İl sınırlarında büyükşehir belediyesi modeline geçiş sonrasında Manisa Büyükşsehir Belediyesi için ulaşım bağlamındaki bu projeksiyonlar diğer alanlara da genişletilebilir. Özellikle Ulaşım Koordinasyon Merkezi (UKOME) ve Altyapı Koordinasyon Merkezi (AKOME) büyükşehir belediyesinin varoluş nedenini oluşturan temel koordinasyon hizmetleri konusunda yetki neredeyse tamamıyla büyükşehir belediyesine verilmiştir. İlçe belediyelerinin görev, yetki ve sorumluluklarının ise daha sınırlı ve büyükşehirin koordinasyonunu tamamlayıcı hizmetler olduğu görülmektedir (Ökmen ve diğerleri, 2014:100).

$\mathrm{Bu}$ konuda en somut ve önemli örneklerden birini de altyapı hizmetleri içerisinde yer alan su ve kanalizasyon hizmetleri oluşturmaktadır. Su ve kanalizasyon hizmetlerinde de, il sınırında büyükşehir belediye modeline geçilmesi, il genelinde yönetim, koordinasyon ve halk memnuniyeti bağlamında önemli ölçüde olumlu gelişmeleri beraberinde getireceği gibi, etkinliği ve verimliliği de artırabilir.

İl sınırında büyükşehir belediye modeline geçişle birlikte, Manisa Büyükşehir Belediyesi tarafindan il genelinde tespit edilen bütün su kaynakları içme ve kullanma suyu havzası ilan edilerek koruma altına alınmalıdır. $\mathrm{Bu}$ dönemde, özel mülkiyete konu olan arazilerden çıkan su kaynaklarının bulunduğu gayrimenkuller kamulaştırılabilir. Su havzalarında ağaçlandırma yapılarak ve özel güvenlik ekipleri kurularak il genelindeki su havzaları sürekli denetim altına alınabilir.

$\mathrm{Bu}$ çerçevede Manisa'da içme suyu altyapısı yeniden ele alınmalı ve özellikle depreme dayanıklı malzemelerle sistem güçlendirilmelidir. Manisa Büyükşshir Belediyesi özelinde etkin hizmet planlama ve sunumu konusunda iyi bir örnek de çevre ile ilgili düzenlemelerdir. Çevre konusunda da il sınırında büyükşehir belediye modeline geçilmesi ciddi anlamda olumlu gelişmeleri beraberinde getirebilir. Yeni 
dönemde, Manisa Büyükşehir Belediyesi tarafından ilin bütününü kapsayan atık yönetim çalışmaları yapılmalı, mevcut vahşi depolama alanları kapatılıp, bu alanlarla ilgili rehabilitasyon çalışmaları yapılmalı, il genelinde en uygun alanlarda yeni ve düzenli depolama sahaları oluşturulmalıdır.

$\mathrm{Bu}$ dönemde, Manisa genelinde değerlendirilebilir atıkların kaynağında ayrı toplanmasına başlanarak, bu kapsamda ambalaj atıkları, atık piller, elektronik atıklar, atık yağlar gibi atıkların ayrı toplanması konusunda bütünlük sağlanmaya yönelik çalışmalar yapılabilir. Etkin ve başarılı atık yönetimi sayesinde, il genelinde daha önceki dönemlerde yapılan vahşi depolamalar yüzünden toprakta, yeraltı ve yüzey sularında ve havada oluşan kirlilik yeni dönemde ortadan kaldırılabilir.

İl sınırında büyükşehir belediye modeline geçilmesiyle birlikte, birinci sınıf Gayr-1 Sıhhi Müesseselerin ruhsatlandırılması, denetlenmesi ile birlikte imar planlama çalışmalarının da büyükşehir belediyelerinin yetki alanına girmesiyle, Manisa genelindeki mevcut sanayi tesislerinin sorunları yerelde çözülmeye başlanacaktır. Aynı şekilde bu dönemde kurulan yeni sanayi tesislerinin planlanması, ruhsatlandırılması ve denetlenmesi konusunda yetki karmaşası ortadan kalkarak, işlemler tek elden yürütülmesi mümkün olabilecektir (Ökmen ve diğerleri, 2014:101). 


\section{KAYNAKÇA}

ARIKBOĞA, Erbay (2013), “Geçmişten Geleceğe Büyükşshir Belediye Modeli”, Yerel Politikalar Dergisi, Ocak / Haziran 2013, ss.48-96.

ÇELIK, M. L. ve ALTIPARMAK, C. (2013), Hukuki Açıdan 100 Soruda Yeni Büyükşsehir Belediye Modeli, Seçkin Yayıncılık, Ankara.

GÜL, Hüseyin (2013), "Dünya ve Türkiye Örneklerinde Metropolitan Alan Yönetim Modelleri ve 6360 Sayılı Yasa”, Yerel Politikalar Dergisi, Ocak / Haziran 2013, ss.7-47.

Manisa Belediyesi (1977), Manisa Belediyesi Tarihçe- Belediye Başkanları- Çalışmalar, Emek Matbaası, Manisa.

Manisa Belediyesi (1984), Manisa Belediyesi 1977-1983, Ticaret Matbaacılık TAŞ., İzmir.

Manisa Belediyesi (2010), Stratejik Plan (2010-2014), Manisa.

Manisa Valiliği (1973), Cumhuriyetin 50. Yılında Manisa, Ayyıldız Matbaası Ankara.

Manisa Valiliği Çevre İl Müdürlüğü (1998), Manisa İli Çevre Durum Raporu, Manisa.

Manisa Valiliği (2000), Manisa 2000, Manisa.

Manisa Valiliği (2007), Manisa 2007, Manisa.

Manisa Valiliği (2014), Sayılarla Manisa 2013, Manisa.

ÖKMEN, M., DEMIR, F., ÇAĞATAY, U. ve BAL, V., (2014), Yeni Büyükşehir Sisteminde Optimal Hizmet Sunumu ve Etkinlik - Verimlilik Arayışı: Akhisar Örneğinde Dönüşüm Sürecine Uyumlulaştırma ve Geleceğe Yönelik Projeksiyonlar, Akhisar.

ÖKMEN, M., PARLAK, B. (2013), Kuram ve Uygulamada Yerel Yönetimler - Kavramlar, Yaklaşımlar, Yapılar ve Mevzuat-, Orion Yayınları, Ankara.

TÜIKK (2013), Seçilmiş Göstergelerle Manisa 2012.

http://gen.tobb.org.tr/ggnot/images/bilgi_notu/828_Aral\%C4\%B1k2013D\%C4\%B1sTicaretIstatistikleri.pdf/ 19.06.2014.

http://www.tuik.gov.tr/VeriTabanlari.do?ust_id=113\&vt_id=457/19.06.2014.

http://www3.kalkinma.gov.tr/PortalDesign/PortalControls/WebIcerikGosterim.aspx?Enc=83D5A6FF03C7B 4FC43121E8457331356/19.06.2014 